\title{
Effect of neck movement on endotracheal tube position
}

\author{
Ekta Rai, MD
}

Received: 13 September 2009/Accepted: 20 October 2009/Published online: 31 October 2009

(C) Canadian Anesthesiologists' Society 2009

\section{To the Editor,}

I read with interest the article written by Kim et al. comparing the effects of head movement on endotracheal tube (ETT) position in adults and children. ${ }^{1}$ The results should be interpreted with caution, as the study was undertaken in a heterogeneous population of adults and children. Due to shorter tracheal length in the pediatric population, the margin of safety for tracheal tube-tip displacement is decreased in children. ${ }^{2}$ In their study, the extent of neck rotation was not described in sufficient detail to allow the procedure to be replicated with precision. Furthermore, due to the differential impact of a fixed (rather than a proportional to body size) movement criterion, the fixed arbitrary movement of $1 \mathrm{~cm}$ may have introduced a study design bias in comparing pediatric patients with adult patients.

Finally, while it was interesting that the authors observed significant movement of the ETT more frequently in adults than in children ( $71 \%$ vs $50 \%$, respectively) during flexion, the authors did not report whether there were any adverse events relating to tube malposition, such as endobronchial intubation, accidental extubation, or vocal cord injury. Due to the study limitations and potential design bias, it would appear that further studies targeted to the pediatric age group are warranted. It would be ideal if such a study could conclude that neck movement in relation to tube movement is safe up to a certain degree.

Conflicts of interest None declared.

\section{References}

1. Kim JT, Kim HJ, Ahn W, et al. Head rotation, flexion, and extension alter endotracheal tube position in adults and children. Can J Anesth 2009; 56: 751-6.

2. Weiss $M$, Knirsch W, Kretschmar $O$, et al. Tracheal tube-tip displacement in children during head-neck movement-a radiological assessment. Br J Anaesth 2006; 96: 486-91.
Editor's note: Dr. Kim and colleagues received this letter with an invitation to reply, and respectfully declined the invitation.

E. Rai, MD $(\bowtie)$

Department of Anaesthesiology, Christian Medical College,

Vellore, Tamil Nadu 632004, India

e-mail: drektarai@yahoo.com 